\title{
$\mu$-Opioid Receptor-Mediated Antinociceptive Responses Differ in Men and Women
}

\author{
Jon-Kar Zubieta,, ${ }^{1,2}$ Yolanda R. Smith, ${ }^{3}$ Joshua A. Bueller, ${ }^{1}$ Yanjun Xu, ${ }^{1}$ Michael R. Kilbourn, ${ }^{2}$ \\ Douglas M. Jewett, ${ }^{2}$ Charles R. Meyer, ${ }^{2}$ Robert A. Koeppe, ${ }^{2}$ and Christian S. Stohler ${ }^{4}$ \\ ${ }^{1}$ Department of Psychiatry and Mental Health Research Institute, Departments of ${ }^{2}$ Radiology and ${ }^{3}$ Obstetrics and \\ Gynecology, Medical School, and ${ }^{4}$ Department of Biologic and Materials Sciences, School of Dentistry, \\ University of Michigan, Ann Arbor, Michigan 48109
}

\begin{abstract}
Sex differences in the experience of clinical and experimental pain have been reported. However, the neurobiological sources underlying the variability in pain responses between sexes have not been adequately explored, especially in humans. The endogenous opioid neurotransmitters and $\mu$-opioid receptors are centrally implicated in responses to stress, in the suppression of pain, and in the action of opiate analgesic drugs. Here we examined sex differences in the activation of the $\mu$-opioid system in response to an intensity-controlled sustained deeptissue pain challenge with positron emission tomography and a $\mu$-opioid receptor-selective radiotracer. Twenty-eight young healthy volunteers (14 men and 14 women) were studied during saline control and pain conditions using a double-blind, randomized, and counterbalanced design. Women were scanned during the early follicular phase of their menstrual cycles after ovulatory cycles. Significant sex differences in the regional
\end{abstract}

activation of the $\mu$-opioid system in response to sustained pain were detected compared with saline controls. Men demonstrated larger magnitudes of $\mu$-opioid system activation than women in the anterior thalamus, ventral basal ganglia, and amygdala. Conversely, women demonstrated reductions in the basal state of activation of the $\mu$-opioid system during pain in the nucleus accumbens, an area previously associated with hyperalgesic responses to the blockade of opioid receptors in experimental animals. These data demonstrate that at matched levels of pain intensity, men and women during their follicular phase differ in the magnitude and direction of response of the $\mu$-opioid system in distinct brain nuclei.

Key words: $\mu$-opioid receptors; endogenous opioids; pain; sex differences; positron emission tomography; thalamus; nucleus accumbens; ventral pallidum; substantia innominata; amygdala
Data acquired in animal models and in humans have consolidated the view that pain is a complex experience resulting from interactions between the processing of nociceptive input and the subsequent activation of antinociceptive responses (Watkins and Mayer, 1982; Basbaum and Fields, 1984; Malmberg et al., 1997; Casey, 1999; Jones et al., 1999; Caterina et al., 2000). Neuroimaging studies with markers of metabolic function have confirmed that pain is represented in a number of interconnected brain regions, subserving anticipatory, sensory, and affective components (Treede et al., 1999; Price, 2000). The utilization of radiotracers labeling specific receptor sites and appropriate kinetic models also allow the examination of neurotransmitter release in response to experimental challenges (Laruelle, 2000). Using these techniques, it has been demonstrated that the activation of the $\mu$-opioid system by its endogenous neurotransmitter(s) suppresses sensory and affective qualities of pain in distinct brain structures in humans (Zubieta et al., 2001).

Women tend to exhibit higher perceptual responses to experimentally induced pain, more consistently so for deep or tonic

\footnotetext{
Received Jan. 23, 2002; revised April 1, 2002; accepted April 4, 2002.

This work was supported by Grants RO1 DE 12743 to J.K.Z. and RO1 DE 12059 to C.S.S. from the National Institute of Dental and Craniofacial Research. We acknowledge the contributions of Teresa Woike, and the Nuclear Medicine technologists (Jill M. Rothley, Edward J. McKenna, Andrew R. Weeden, Paul Kison, and Shayna Huber) of the PET Center at the University of Michigan to the performance of these studies.

Correspondence should be addressed to Dr. Jon-Kar Zubieta, Mental Health Research Institute, 205 Zina Pitcher Place, Ann Arbor, MI 48109-0720. E-mail: zubieta@umich.edu.

Copyright (C) 2002 Society for Neuroscience $\quad 0270-6474 / 02 / 225100-08 \$ 15.00 / 0$
}

pain models (Fillingim and Maixner, 1995). In addition, many persistent pain conditions have a higher prevalence in women than men (Unruh, 1996). However, the neurobiological mechanisms underlying these sex differences are unknown. Sex differences in supraspinal metabolic responses to phasic heat pain have been described in humans, however without controlling for menstrual cycle phase (Paulson et al., 1998). In that study, women experienced the same painful stimulus as more intense than men, and their brain regional responses were also greater in regions implicated in the processing of pain intensity (Coghill et al., 1999). Under these conditions, it was not possible to separate sex differences in pain sensitivity from those that may be attributable to central regulatory influences.

The present report focuses on the function of the $\mu$-opioid receptor system as a possible candidate underlying sex differences in the regulation of the pain experience. $\mu$-Opioid receptors mediate the action of exogenously administered opiate drugs and antinociceptive responses to sustained or repetitive stressful and painf ul stimuli (Watkins and Mayer, 1982; Akil et al., 1984; Terman et al., 1984; Matthes et al., 1996). Sex differences in the potency of $\mu$-opioid analgesic drugs have been shown in behavioral and neurochemical studies in animal models (Baamonde et al., 1989; Cicero et al., 1996, 1999; Tershner et al., 2000); however, data in humans is limited and less conclusive in that regard (Kest et al., 2000; Zacny, 2001). Brain regional $\mu$-opioid receptor concentrations have also been shown to differ between men and in women, and may also be regulated by age and circulating gonadal steroids (Hammer, 


\begin{tabular}{lcc}
\hline $\begin{array}{l}\text { Table 1. Demographics and psychophysiological variables during } \\
\text { sustained pain }\end{array}$ & \\
& Men & Women \\
\hline Age & $25 \pm 2$ & $24 \pm 3$ \\
Education (years) & $18 \pm 2$ & $17 \pm 2$ \\
Average VAS intensity ratings & $36.0 \pm 9.3$ & $40.3 \pm 7.5$ \\
Average infusion rate ( $\mu$ l/min) & $121.0 \pm 57.3$ & $104.8 \pm 50.5$ \\
$0-10$ min & $72.6 \pm 58.8$ & $65.1 \pm 46.4$ \\
10-20 min & $161.3 \pm 65.3$ & $136.9 \pm 53.0$ \\
MPQ sensory & $14.7 \pm 4.6$ & $16.7 \pm 5.6$ \\
MPQ affective & $2.6 \pm 1.9$ & $2.4 \pm 2.1$ \\
MPQ total & $23.6 \pm 8.1$ & $26.8 \pm 8.1$ \\
PANAS negative affect & $5.8 \pm 4.8$ & $8.5 \pm 6.9$ \\
PANAS positive affect & $13.6 \pm 5.9$ & $11.6 \pm 6.4$ \\
Estradiol (pg/ml) & & $43.7 \pm 28.8$ \\
Progesterone (ng/ml) & & $<1.0$ \\
\hline Data & &
\end{tabular}

Data show the mean \pm SD of demographics, variables related to the painful challenge, and gonadal steroid levels. These include the average VAS intensity ratings of the volunteers (obtained every $15 \mathrm{sec}$ for the duration of the study), average infusion rate, and ratings of the pain experience and internal affective state during the painful challenge. The average infusion rate is also divided into early $(0-10 \mathrm{~min})$ and later $(10-20 \mathrm{~min})$ stages of pain, because of the possible differential contribution of $\mu$-opioid mechanisms to various stages of pain. No significant differences between groups were obtained for any of those variables (unpaired, two-tailed $t$ tests; $p>0.05)$. Estradiol and progesterone levels are reported for women only.

1990; Gabilondo et al., 1995; Smith et al., 1998; Zubieta et al., 1999).

The present work expands this scope of research and examines whether sex differences exist in the response of the $\mu$-opioid system to a painful stimulus. Previously described interindividual variations and sex differences in pain thresholds (Fillingim and Maixner, 1995) necessitated the utilization of an intensitycontrolled experimental pain model to ensure the comparability of data between subjects and sexes (Zhang et al., 1993). Measures of in vivo $\mu$-opioid receptor availability were obtained during pain and saline control conditions. Increases in $\mu$-opioid system activation with pain are then observed as reductions in in vivo receptor availability with respect to saline controls.

\section{MATERIALS AND METHODS}

Twenty-eight healthy volunteers (20-30 years of age; 14 men and 14 women) were studied. Volunteers were right-handed nonsmokers who had no personal history of medical illness, psychiatric illness, and substance abuse or dependence as well as no family history of inheritable illnesses. Volunteers were not taking psychotropic medications or hormone treatments and did not exercise in excess of $1 \mathrm{hr}$ three times per week. Women had not used hormonal birth control for at least 6 months, had regular menstrual cycles, and were scanned during the follicular phase of their menstrual cycles (2-9 d after the onset of menses), ascertained by plasma levels of estradiol and progesterone immediately before scanning (Table 1). Testosterone plasma levels were also obtained at that time in men. To further standardize the hormonal milieu of the women volunteers, the presence of ovulatory cycles before scanning was also determined by a progesterone level of $>3 \mathrm{ng} / \mathrm{ml}$ during the luteal phase of the preceding menstrual cycle. Subjects were instructed not to drink alcohol for at least $24 \mathrm{hr}$, nor to exercise or eat before the study. All studies were conducted in the morning, between 8-11 A.M. Written informed consent was obtained in all cases. All of the procedures used were approved by the University of Michigan Investigational Review Board for Human Subject Use and the Radiation Safety Committee.

Pain and saline control conditions were introduced $20 \mathrm{~min}$ after radiotracer administration, in a double-blind, randomized (for men and women separately), and counterbalanced design (with one-half of the volunteers receiving pain first and one-half receiving the saline control). A steady state of muscle pain was maintained 20-40 min after tracer administration by a computer-controlled system through the infusion of medication-grade hypertonic saline $(5 \%)$ into the masseter muscle. In this model of sustained deep somatic pain, the intensity of the painful stimulus is standardized across subjects, as described in detail previously (Zhang et al., 1993; Stohler and Kowalski, 1999). Briefly, after a standard $15 \mathrm{sec}$ bolus administration, an electronic version of a $10 \mathrm{~cm}$ visual analog scale (VAS) is used by the subject to rate pain intensity once every $15 \mathrm{sec}$. This signal is fed back to the computer via an analog-digital board, which then adjusts the infusion rate so that pain is maintained at VAS intensity ratings of 40-60 for the duration of the challenge. Subjects are informed that the lower end on the scale denotes "no pain," whereas the upper bound represents the "most intense pain imaginable." The control condition consisted of isotonic saline infused at the average rate required to achieve 50 VAS ratings and was applied in the masseter muscle opposite to where pain was induced. The location of the algesic and control infusions (right-left) was also randomized and counterbalanced to maintain the double-blind. The sensory and pain-specific affective qualities of the painful stimulus were rated after completion of each positron emission tomography (PET) scan with the McGill pain questionnaire (MPQ) (Melzack and Katz, 2000). The internal emotional state of the volunteers was rated at the same time with the positive and negative affectivity scale (PANAS) (Watson et al., 1988).

Magnetic resonance imaging (MRI) scans were acquired in all subjects on a 1.5 tesla scanner (Signa; General Electric, Milwaukee, WI). Acquisition sequences were axial spoiled gradient-recalled acquisition in a steady state (SPGR) inverse recovery (IR)-Prep MR [echo time (TE), 5.5; repetition time (TR), 14; image time, 300; flip angle, $20^{\circ}$; number of excitations (NEX), 1; 124 contiguous images; $1.5 \mathrm{~mm}$ thickness] followed by axial T2 and proton density images (TR, 4000; TE, 20 and 100, respectively; NEX, 1; 62 contiguous images; $3 \mathrm{~mm}$ thickness). All MR scans were reviewed by a neuroradiologist to rule out gross structural brain abnormalities before PET scanning.

PET scans were acquired with a Siemens (CTI, Knoxville, TN) ECAT Exact scanner in three-dimensional mode with septa retracted. Participants were positioned in the PET scanner gantry, and two intravenous (antecubital) lines were placed. A light forehead restraint was used to eliminate intrascan head movement. $\left[{ }^{11} \mathrm{C}\right]$ carfentanil was synthesized at high specific activity $(>2000 \mathrm{Ci} / \mathrm{mmol})$ by the reaction of ${ }^{11} \mathrm{C}$ methyliodide and a nonmethyl precursor as described previously (Dannals et al., 1985), with minor modifications to improve its synthetic yield (Jewett, 2001); 10-15 mCi (370-555 MBq) were administered to each subject for each of the two PET scans. The two administrations were separated by $2 \mathrm{hr}$ to allow for tracer decay. The total mass of carfentanil injected was $0.028 \pm 0.004 \mu \mathrm{g} / \mathrm{kg}$ per scan, ensuring that the compound was administered in tracer quantities (i.e., subpharmacological doses). Receptor occupancy by carfentanil was calculated to be between 0.2 and $0.6 \%$ for brain regions with low, intermediate, and high $\mu$-opioid receptor concentrations, based on the mass of carfentanil administered and the known concentration of $\mu$ receptors in the postmortem human brain (Gross-Isseroff et al., 1990; Gabilondo et al., 1995). The mass of carfentanil administered did not differ between men and women or between saline control and pain scans within each group. Fifty-five percent of the $\left[{ }^{11} \mathrm{C}\right]$ carfentanil dose was administered as a bolus, and the remainder was administered as a continuous inf usion using a computer-controlled pump to achieve steady-state tracer levels. Nineteen sets of scans were acquired over $70 \mathrm{~min}$ with an increasing duration (30 $\mathrm{sec}$ up to $10 \mathrm{~min}$ ). Images were reconstructed using filtered back-projection with a Hanning 0.5 filter and included both measured attenuation and scatter corrections. Dynamic images were coregistered to each other and the intercommisural line using automated computer routines (Minoshima et al., 1993). Image data were then transformed on a voxel-by-voxel basis into two sets of parametric maps: (1) a tracer transport measure $\left(K_{1}\right.$ ratio) and $(2)$ a "receptor-related" measure [distribution volume ratio (DVR)]; the latter used data obtained 20-70 min after tracer administration for saline control and pain studies. To avoid the need for arterial blood sampling, the tracer transport and binding measures were calculated using a modified Logan graphical analysis (Logan et al., 1996), using the occipital cortex (an area devoid of $\mu$-opioid receptors) as the reference region. With the tracer administration protocol used, the Logan plot becomes linear by $5-7 \mathrm{~min}$ after the start of radiotracer administration, with its slope being the DVR, a measure equal to the $\left(B_{\max } / K_{\mathrm{d}}\right)+1$ for this receptor site and radiotracer. $B_{\max } / K_{\mathrm{d}}$ (or DVR-1) is the receptor-related measure ( $\mu$-opioid receptor availability, or binding potential). $K_{1}$ and DVR images for each experimental period and MR images were coreg- 
Figure 1. Changes in the state of activation of the $\mu$-opioid system during intensity-controlled sustained muscle pain in males and females. Brain areas are shown in which significant changes in regional in vivo $\mu$-opioid receptor availability from saline control to sustained pain were obtained in men (left side of the image) and women (right side of the image). These are shown from anterior (top part of the image) to posterior (bottom part of the image), with their corresponding ICBM $y$ coordinates: in males, nucleus accumbens, amygdala, ventral pallidum/substantia innominata, and thalamus; in females, nucleus accumbens, and ventral pallidum/substantia innominata. Regions in which increased activation or reductions in the state of activation were obtained are indicated at each level. $Z$ scores of statistical significance are represented by the pseudocolor scale on the right side of the image and are superimposed over an anatomically standardized MRI image in coronal views. The left side corresponds to the side ipsilateral to pain, and the right side corresponds to the contralateral side.

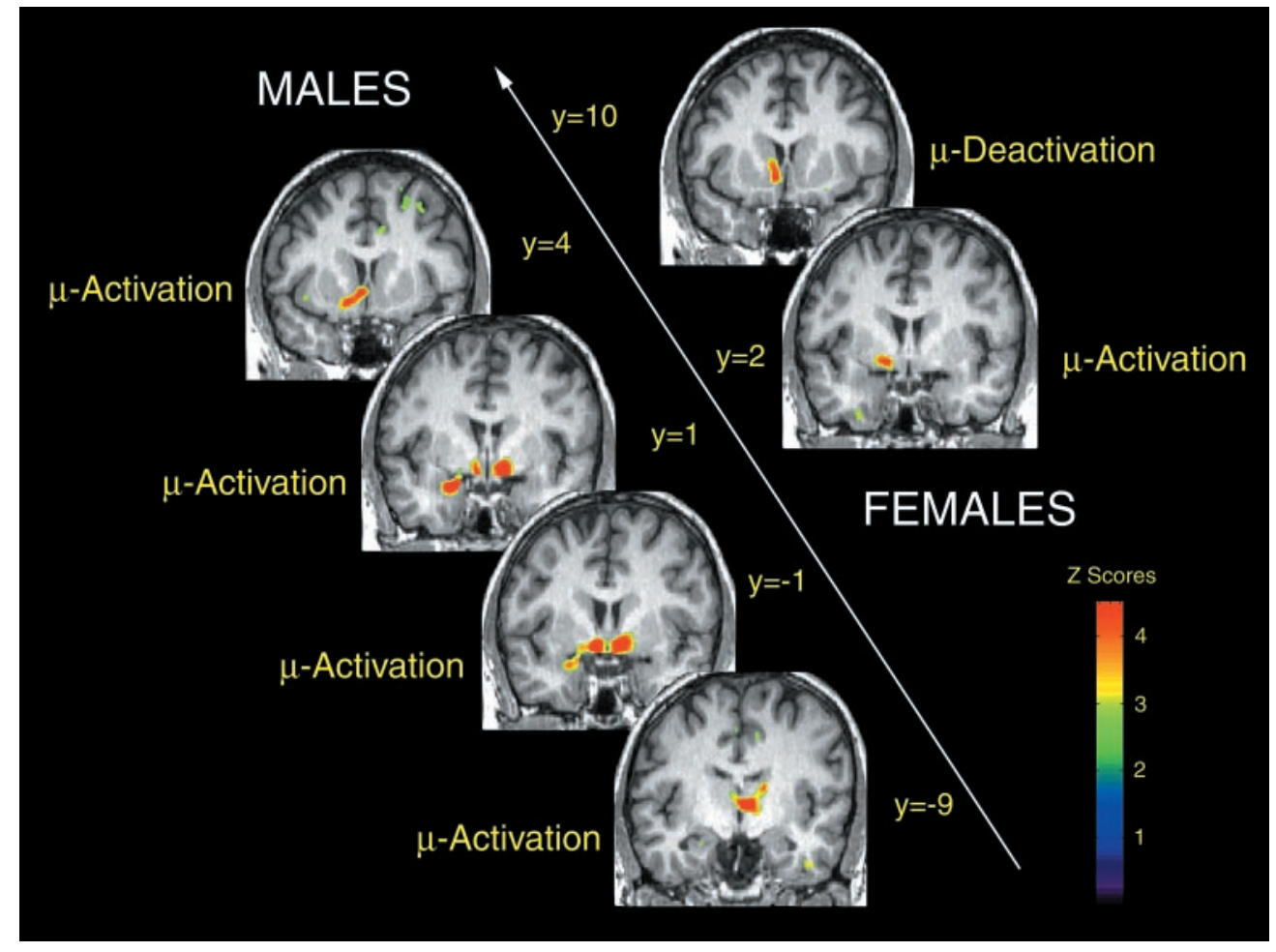

istered to each other and to the International Consortium for Brain Mapping (ICBM) stereotactic atlas orientation (Meyer et al., 1997).

Statistical parametric maps of differences between conditions (control vs pain) were generated by anatomically standardizing the T1-SPGR MRI of each subject to the ICBM stereotactic atlas coordinates, with subsequent application of this transformation to the $\mu$-opioid receptor binding maps (Meyer et al., 1997). The accuracy of coregistration and nonlinear warping algorithms was confirmed for each subject individually by comparing the transformed MRI and PET images with each other and the ICBM atlas template. Before nonlinear warping, image data were flipped so that the side of the painful challenge (induced on the right or the left masseter muscle) was located on the same side of the image for all subjects. Image data are therefore presented as "ipsilateral" or "contralateral" to the painful stimulus, regardless of the actual location (right-left). Differences between conditions and sex groups were then mapped into stereotactic space using $z$ maps of statistical significance with statistical parametric mapping software, version 99 (SPM'99) (Wellcome Department of Cognitive Neurology, London, UK) and Matlab software (Mathworks, Natick, MA), with a general linear model and correction for multiple comparisons (Friston et al., 1995). No global normalization was applied to the data; therefore, the calculations presented are based on absolute $B_{\max } / K_{\mathrm{d}}$ estimates. Only regions with specific $\mu$-opioid receptor binding were included in the analyses (voxels with DVR values of $>1.2$ times the mean global image value for $\mu$-opioid receptor images as calculated with SPM'99). To compensate for small residual anatomic variations across subjects and to improve signal to noise ratios, a three-dimensional Gaussian filter (full width at halfmaximum of $6 \mathrm{~mm}$ ) was applied to each scan. For each subtraction analysis, one sample or two sample two-tailed $t$ statistic values were calculated for each voxel using the pooled variance across voxels (Worsley et al., 1992). Areas of significant differences were detected using a statistical threshold that controls a type I error rate at $p=0.05$ for multiple comparisons, which is estimated using the Euler characteristic (Worsley, 1994) based on the number of voxels in the gray matter and image smoothness (Friston et al., 1991). This typically varies from $z=$ 4.3-4.6 in our studies for peak analyses, at a final resolution of $\sim 10 \mathrm{~mm}$. $Z$ scores were also deemed significant if they reached statistical thresholds after correction for the size of the cluster under consideration (Friston et al., 1994).

Pearson correlations were also calculated between the changes in $\mu$-opioid receptor availability between conditions and the change in MPQ pain ratings and PANAS negative and positive affect scores, at $p<$
0.05. For this purpose, binding values were obtained for the regions identified as showing differences in pain activation between the sexes, including those voxels showing levels of significance of $p<0.001$, uncorrected for multiple comparisons.

\section{RESULTS}

Controlling for pain intensity resulted in no significant differences in subjective responses between men and women as captured by the VAS scores or MPQ total, sensory, or affective ratings (Table 1). Similarly, the change in PANAS negative and positive affect scores between saline control and pain conditions did not differ significantly between sexes (change in negative affect scores: men, $3.8 \pm 5.0$; women, $6.9 \pm 6.3 ; \mathrm{df}=26 ; t=1.46 ; p=0.16$; change in positive affect scores: men, $-2.5 \pm 5.2$; women, $-2.3 \pm 4.0$; df $=26 ; t=0.12 ; p=0.9)$ (also see Table 1$)$.

Sex differences in baseline (control scan) $\mu$-opioid receptor binding were first tested for statistical significance using twosample $t$ tests, on a voxel-by-voxel basis. Significantly higher baseline (control) $\mu$-opioid binding was observed in females with respect to males in the amygdala contralateral to the pain (ipsilateral to saline control) [men, $1.23 \pm 0.27$; women, $1.54 \pm 0.46$; $x, y, z$ coordinates (in mm), $19,-5,-18 ; z=4.36 ; p=0.04$ after correction for multiple comparisons].

The presence of regional $\mu$-opioid system activation induced by sustained pain (reflected by reductions in $B_{\text {max }} / K_{\mathrm{d}}$ from saline control to pain scans) was first examined in males and females separately (Fig. 1). In males, significant activation of this system was detected contralateral to the painful stimulus in the anterior thalamus $[x, y, z$ coordinates (in $\mathrm{mm}$ ) $, 4,-9,4 ; z$ score $=6.22 ; p<$ 0.0001 after correction for multiple comparisons] and ventral pallidum/substantia innominata $(x, y, z$ coordinates, $10,-1,-11$; $z$ score $=6.64 ; p<0.0001)$. Ipsilaterally, significant activation was detected in an area that included the nucleus accumbens and the adjacent ventral pallidum/substantia innominata (location of peak change; $x, y, z$ coordinates, $-8,4,-10 ; z$ score $=6.00 ; p<$ 


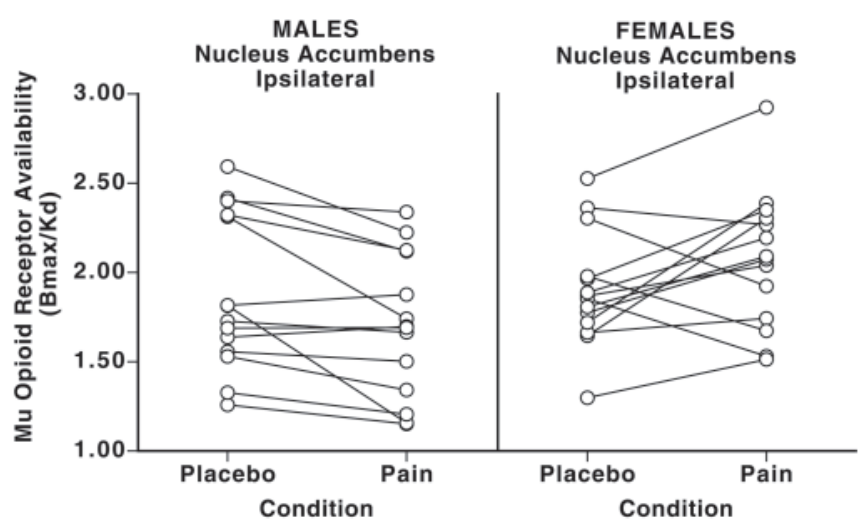

Figure 2. Individual data for baseline (control) and pain-induced changes in nucleus accumbens $\mu$-opioid in vivo receptor availability in men and women. Individual data points for $B_{\max } / K_{\mathrm{d}}$ values obtained in the nucleus accumbens for the sample of men and women studied during placebo and pain conditions are shown. Note the consistent reductions in pain-induced in vivo receptor availability in males and the larger variability in the responses of females to the same stimulus intensity. Four women showed increases in $\mu$-opioid system activation (lower in vivo $\mu$-opioid receptor availability during pain), and the reminder showed reductions in the state of activation of the system (increase in in vivo receptor availability).

$0.0001)$, as well as in the amygdala $(x, y, z$ coordinates, $-24,1$, $-20 ; z$ score $=5.54 ; p<0.001)$. When taking into account the size of the region involved (cluster-level correction for multiple comparisons) (Friston et al., 1994), the contralateral anterior insular cortex also registered significant $\mu$-opioid system activation during sustained pain $(x, y, z$ coordinates, $38,23,1 ; z$ score $=$ $3.59 ; p=0.01)$. In females, the only region showing significant $\mu$-opioid system activation at this level of pain was localized in the ipsilateral ventral pallidum/substantia innominata $(x, y, z$ coordinates, $-14,2,-7 ; z$ score $=4.58 ; p<0.05$ after correction for multiple comparisons).

Significant reductions in the state of activation of the $\mu$-opioid system, observed experimentally as increases in receptor availability in vivo from saline control to pain, were also detected, but only in females. This effect was localized in the nucleus accumbens ipsilateral to the painful challenge $(x, y, z$ coordinates, -7 , $10,-7 ; z$ score $=6.07 ; p<0.0001$ after correction for multiple comparisons) (Fig. 1). In this region, the changes in $\mu$-opioid receptor availability from saline control to pain conditions were also more variable in females than in males. Four of the women demonstrated some degree of activation of the $\mu$-opioid system, and the reminder demonstrated reductions in its state of activation. It was also observed that one of the female volunteers registered both the highest $\mu$-opioid receptor binding levels at baseline (control) and the largest reductions in activation with pain in this region (Fig. 2). To ensure that the presence of an outlier would not bias the results in the direction of a positive finding, the data were also analyzed with the exclusion of that volunteer. However, the statistical significance of the effect (reductions in neurotransmitter release and decreased state of activation of the $\mu$-opioid system in the nucleus accumbens in women) was still maintained $(x, y, z$ coordinates, $-7,10,-6 ; z$ score $=5.20 ; p=0.003$ after correction for multiple comparisons).

The presence of statistically significant sex differences in the activation of the $\mu$-opioid system with pain were then examined (two sample, two-tailed unpaired $t$ tests between sexes). Significantly higher magnitudes of $\mu$-opioid system activation were confirmed in men compared with women in the contralateral anterior thalamus, ventral pallidum/substantia innominata, and ipsilateral nucleus accumbens, ventral pallidum/substantia innominata, and amygdala, but not in the insular cortex (Table 2, Fig. 3). The pain-induced reductions in the state of activation of the $\mu$-opioid system in the ipsilateral nucleus accumbens of women also reached the statistical threshold of significance in the comparison between the sexes (Table 2, Fig. 3).

To further examine these findings, correlational analyses were performed between the changes in the state of activation of the $\mu$-opioid system for the regions in which significant sex differences were observed and the change in MPQ and PANAS ratings between conditions (Pearson correlations at a significance level of $p<0.05)$. When all of the subjects were included in the analyses, the magnitude of activation of the $\mu$-opioid system in the ipsilateral amygdala and nucleus accumbens was negatively correlated with MPQ sensory scores $(\mathrm{df}=26, r=-0.49, p=0.008$, and $\mathrm{df}=$ $26, r=-0.54, p=0.003$, respectively). The activation in the contralateral ventral pallidum/substantia innominata also reached statistically significant levels of negative correlation with the change in PANAS negative affect scores ( $\mathrm{df}=26 ; r=-0.38$; $p=0.05)$.

When the correlations for men and women were examined separately, sensory MPQ scores were negatively correlated with the magnitude of $\mu$-opioid system activation in the ipsilateral accumbens of men and women (men, $r=-0.68$, df $=12, p<$ 0.01 ; women, $r=-0.56$, $\mathrm{df}=12, p<0.05)$ and in the ipsilateral amygdala of women $(r=-0.68$; df $=12 ; p<0.01)$ (men, $r=$ -0.14 , df $=12, p=0.6$ ) (Fig. 4). MPQ pain-specific affective ratings were negatively correlated with the magnitude of $\mu$-opioid system activation in the thalamus contralateral to the painful challenge in men $(r=-0.55$; df $=13 ; p=0.04)$ (women, $r=$ $-0.1, \mathrm{df}=12, p=0.8$ ) (Fig. 4). No significant correlations were observed between baseline $\mu$-opioid receptor binding measures or the change in $\mu$-opioid receptor availability with pain in these regions, and plasma levels of estradiol in women or testosterone in men $(p>0.05)$.

\section{DISCUSSION}

This report demonstrates the presence of significant sex differences in the magnitude and direction of recruitment of the $\mu$-opioid system in response to an intensity-matched, sustained deep somatic pain challenge in humans. Some of these effects were observed in brain regions (thalamus, nucleus accumbens, and amygdala) previously implicated in $\mu$-opioid-mediated antinociception in animal models (Carr and Bak, 1988; Bushnell and Duncan, 1989; Manning, 1998; Gear et al., 1999; Harte et al., 2000) and more recently in humans (Zubieta et al., 2001). In addition, a previously unrecognized involvement of the ventral pallidum/substantia innominata in $\mu$-opioid receptor-mediated responses to pain is also shown.

The inherent variability in plasma gonadal steroids in women and the possible influence of estradiol and progesterone on opioid mechanisms (Eckersell et al., 1998; Smith et al., 1998; Sinchak and Micevych 2001) required the standardization of the hormonal milieu of the volunteers. This was achieved by performing the studies during the early follicular phase of the menstrual cycle, therefore reflecting a low-estradiol, low-progesterone state. Under these conditions, males demonstrated higher magnitudes of endogenous opioid release and $\mu$-opioid system activation in brain regions implicated in the suppression of sensory and affective qualities of pain. $\mu$-Opioid system activation in the ventral 
Table 2. Sex differences in brain regional activation of $\mu$-opioid systems during intensity-controlled sustained pain

\begin{tabular}{|c|c|c|c|c|c|c|c|c|c|}
\hline \multirow[b]{2}{*}{ Regions } & \multicolumn{3}{|l|}{$\underline{\text { Men }}$} & \multicolumn{3}{|l|}{ Women } & \multirow{2}{*}{$\begin{array}{l}\text { Coordinates } \\
(x, y, z)\end{array}$} & \multicolumn{2}{|c|}{ Cluster } \\
\hline & Control & Pain & $\% \Delta$ & Control & Pain & $\% \Delta$ & & Size & $Z$ \\
\hline \multicolumn{10}{|c|}{$\mu$-Opioid system activation, men $>$ women } \\
\hline THA (C) & $2.69 \pm 0.53$ & $2.47 \pm 0.41$ & -7.1 & $2.54 \pm 0.47$ & $2.67 \pm 0.49$ & 5.4 & $3,-10,4$ & 1862 & 6.71 \\
\hline $\mathrm{VP}(\mathrm{C})$ & $1.70 \pm 0.52$ & $1.49 \pm 0.34$ & -10.3 & $1.70 \pm 0.29$ & $1.72 \pm 0.35$ & 1.5 & $10,-1,-10$ & 759 & 5.45 \\
\hline NAC/VP (I) & $1.89 \pm 0.44$ & $1.70 \pm 0.40$ & -9.2 & $2.03 \pm 0.28$ & $2.13 \pm 0.32$ & 5.3 & $-6,5,-10$ & 988 & 4.40 \\
\hline $\operatorname{AMY}(\mathrm{I})$ & $1.59 \pm 0.40$ & $1.42 \pm 0.27$ & -8.6 & $1.60 \pm 0.34$ & $1.68 \pm 0.36$ & 5.4 & $-25,-2,-22$ & 931 & 4.42 \\
\hline \multicolumn{10}{|c|}{$\mu$-Opioid system deactivation, women $>$ men } \\
\hline NAC (I) & $1.92 \pm 0.32$ & $1.74 \pm 0.40$ & -8.2 & $1.60 \pm 0.43$ & $2.10 \pm 0.38$ & 10.4 & $-7,13,-4$ & 1073 & 5.20 \\
\hline
\end{tabular}

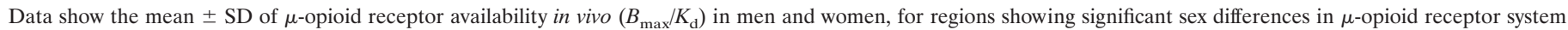

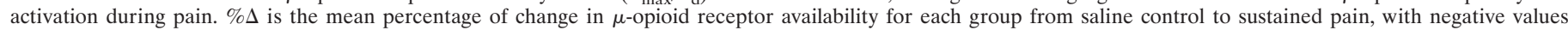

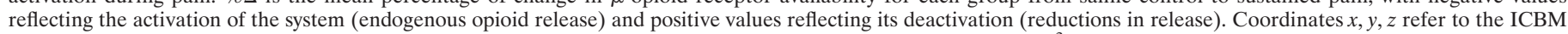

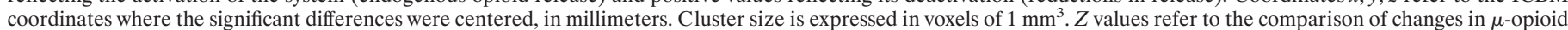

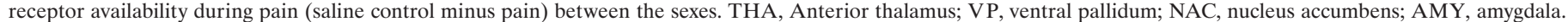

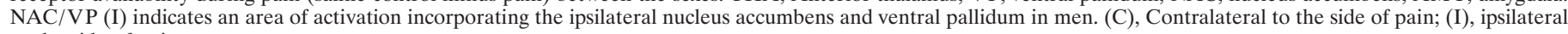
to the side of pain.

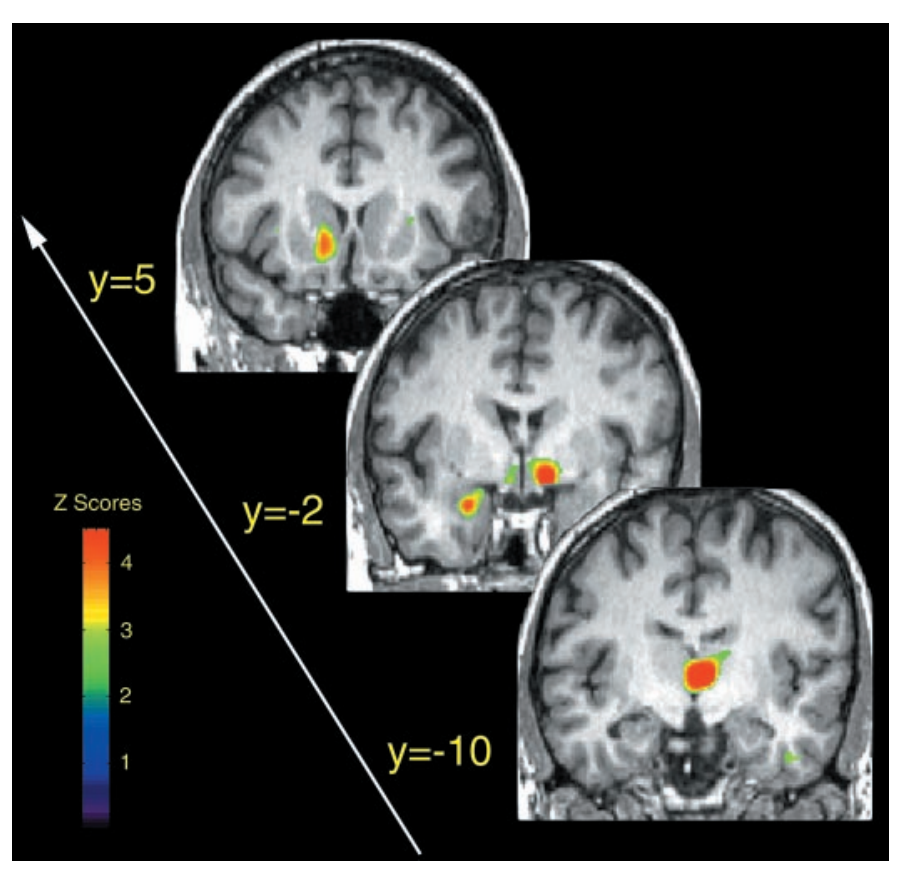

Figure 3. Sex differences in the activation of the $\mu$-opioid system during intensity-controlled sustained muscle pain. Brain areas are shown in which significantly larger magnitudes of $\mu$-opioid system activation were observed in males compared with females during their early follicular phase. These are shown from anterior (top part of the image) to posterior (bottom part of the image), with their corresponding ICBM $y$ coordinates: nucleus accumbens, amygdala, ventral pallidum/substantia innominata, and thalamus. $Z$ scores of statistical significance are represented by the pseudocolor scale on the left side of the figure and are superimposed over an anatomically standardized MRI image in coronal views.

pallidum/substantia innominata was also negatively correlated with increases in negative affect scores during pain, as quantified by the PANAS.

The results obtained would suggest that, at matched pain intensities, the $\mu$-opioid receptor system is less active during the follicular phase of women than in men. Alternatively, they may indicate a lesser involvement of $\mu$-opioid mechanisms in the modulation of pain of females. The latter possibility would be consistent with clinical data showing that other receptor systems may support the suppression of pain in women (e.g., $\kappa$-opioid receptors) (Gear et al., 1996). However, extensive literature on the subject has also demonstrated that the $\mu$-opioid receptor system is essential for the induction of antinociceptive responses in male and female rodents (Rubinstein et al., 1996; Sora et al., 1997). If that is indeed the case, the results imply that during their follicular phase, when gonadal steroid levels are low, women are less capable of suppressing deep somatic pain by the activation of this mechanism. In this regard, a lower tolerance of women to more prolonged or repetitive pain challenges, when $\mu$-opioid receptor-mediated antinociceptive responses are typically activated (Watkins and Mayer, 1982), is consistently observed in human research literature (Fillingim and Maixner, 1995). In our study, the infusion rates necessary to maintain pain at a constant level were also somewhat lower in women than in men, particularly during the second half of the pain challenge, albeit with high levels of interindividual variability and not reaching statistical significance. This is consistent with the lesser activation of antinociceptive responses observed in follicular phase women compared with men.

Studies in rodents and nonhuman primate models have typically reported a higher sensitivity to the antinociceptive effects of $\mu$-opioid receptor agonists in males, compared with intact or ovariectomized females of the same species (Cicero et al., 1996, 1999; Negus and Mello, 1999). One exception has been the finding of a higher sensitivity to $\mu$-opioid agonists in the periaqueductal gray of female compared with male rodents (Tershner et al., 2000). Sex differences also appear to be dependent on genotype, with sensitivity to $\mu$-opioid agonists presenting in various directions depending on the rodent strains used and also being regulated by circulating gonadal steroids (Mogil et al., 2000). In human subjects, incomplete evidence suggests a higher sensitivity to $\mu$-opioid receptor agonists in women than in men, at least for some of their subjective effects (Miaskowski and Levine, 1999; Kest et al., 2000; Zacny, 2001). This latter information appears consistent with postmortem neurochemical data (Gross-Isseroff et al., 1990; Gabilondo et al., 1995) and in vivo neuroimaging studies in humans (Zubieta et al., 1999) showing higher regional $\mu$-opioid receptor concentrations in women than in men, also regulated by the effects of age, and possibly, gonadal steroids. In the present report, using subjects within a narrow age range and controlling for phase of the menstrual cycle, women still demonstrated higher $\mu$-opioid receptor concentrations in the amygdala region. Given the known involvement of amygdala $\mu$-opioid receptors in antinociception (Manning, 1998; Zubieta et al., 2001), 


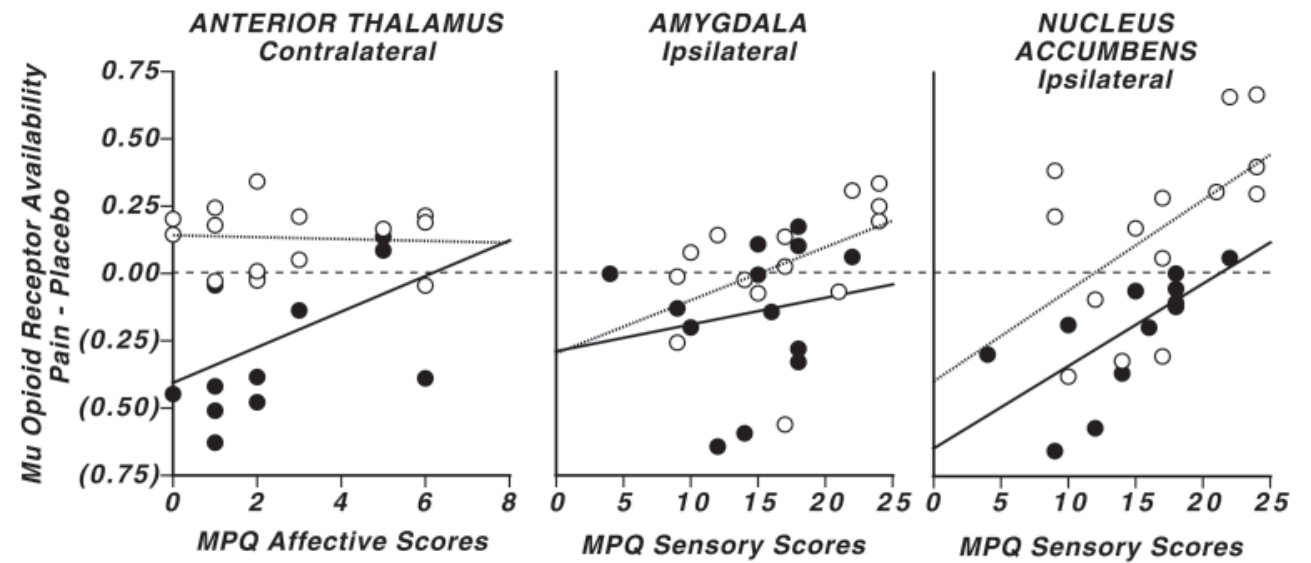

bens) are shown. The dashed line depicts 0.00 change and is pre
Figure 4. Correlations between the magnitude of regional activation of the $\mu$-opioid system and MPQ affective and sensory subscale scores in males and females. Graphs show the individual data points and correlations between the changes in in vivo $\mu$-opioid receptor availability from placebo to pain conditions in males (filled circles and solid lines) and females (open circles and dotted lines), as well as MPQ affective and sensory subscale scores. Negative values of change (in parentheses) reflect the activation of the $\mu$-opioid system and reductions in $\mu$-opioid receptor availability in vivo. Correlations with MPQ affective scores (contralateral anterior thalamus) and with MPQ sensory scores (ipsilateral amygdala and accumesented as a visual aid in data interpretation. this finding is consistent with the observations that women, by virtue of their higher regional $\mu$-opioid receptor concentrations, would be more sensitive to the effects of exogenously administered $\mu$-opioid agonists.

In contrast to the studies examining the effect of exogenously administered $\mu$-opioid agonists, animal models of stress, sustained pain, and conditioned analgesia more consistently show that female rodents have less prominent endogenous opioidmediated analgesic responses than males. These sex differences also appear to be more pronounced after ovariectomy or when gonadal steroid levels are low (Romero and Bodnar, 1986; Kavaliers and Colwell, 1991; Aloisi et al., 1994a,b; Mogil and Belknap, 1997; Stock et al., 2001), similar to our results. Of interest, the function of the endogenous opioid system appears enhanced when levels of estradiol and progesterone are high, mimicking the endocrine status of pregnancy (Dawson-Basoa and Gintzler, 1993). This may imply differences in the manner by which males and females regulate pain, perhaps preserved through evolution. In the latter group, more complex modulatory influences, such as those of gonadal steroids, may be necessary to maintain homeostasis under certain conditions (e.g., pregnancy). A more comprehensive examination of gonadal steroid influences on $\mu$-opioid system function in humans will require the systematic manipulation of estradiol and progesterone plasma levels. In this regard, a number of studies have examined the possible influence of menstrual cycle phase on responses to various forms of clinical and experimental pain. However, the data obtained in this manner are often difficult to interpret because of interindividual variations in gonadal steroid levels and the inability to separate the effects of estradiol from those of progesterone in studies performed during the luteal phase of the menstrual cycle (Smith et al., 1998). In addition, conflicting results are observed depending on whether the pain studied is clinical or experimental and, in the latter case, whether it is of short or longer duration (Fillingim and Ness, 2000). We did not observe any significant correlations between plasma levels of estradiol or testosterone and $\mu$-opioid receptor binding and activation during pain in the present study. In this regard, it should be noted that all experiments were performed when estradiol and progesterone levels were low and within a narrow range, reducing the possibility of defining the effects of these gonadal steroids.

At the present time, reliable measurements of receptor binding or $\mu$-opioid system activation in the periaqueductal gray are difficult to obtain, because of the resolution of human PET and the small cross-sectional diameter of this structure. Therefore, the presence of more effective $\mu$-opioid receptor-mediated antinociceptive responses at this level (Tershner et al., 2000) could not be determined. In all the regions in which significant sex differences were obtained (thalamus, nucleus accumbens, ventral pallidum/ substantia innominata, and amygdala), men activated the $\mu$-opioid system to a larger extent than women during their follicular phase. In addition, an unexpected result was that pain induced a reduced state of activation of the $\mu$-opioid system in the ipsilateral nucleus accumbens in the majority of the women studied. The magnitude of this deactivation was also associated with higher ratings of the pain experience, as captured by the MPQ sensory subscale.

This finding suggests the presence of a pain disinhibiting effect mediated by the $\mu$-opioid system at the level of the nucleus accumbens in the follicular phase of women. The statistical significance of this result was maintained after elimination of the female volunteer with the largest change in this region, demonstrating that it could not be solely ascribed to an outlier. The nucleus accumbens lies at the interface of sensorimotor and limbic systems, and together with the amygdala and the ventral pallidum/substantia innominata, forms part of a circuit involved in the integration of cognitive, affective, and motor responses (Mogenson and Yang, 1991). It is also part of a recently identified ascending antinociceptive pathway that is regulated by endogenous opioids and $\mu$-opioid receptors (Gear and Levine, 1995; Gear et al., 1999). In those studies, it was also observed that the application of an opioid receptor antagonist in the nucleus accumbens induced hyperalgesia in experimental animals, suggesting a tonic release of endogenous opioid peptides at baseline conditions (Gear and Levine, 1995).

Theoretically, a reduction in the baseline suppressive activity of the nucleus accumbens $\mu$-opioid system would in turn allow the more effective transmission of nociceptive information to its efferent regions. These include prominent outputs to the ventral pallidum and associated limbic and paralimbic structures (i.e., amygdala and prefrontal cortex), where pain information would become subject to additional processing and contextualization by environmental influences. Of interest, interindividual variations in the nucleus accumbens response were also observed. Some women demonstrated an increased activation of the system $(n=$ $4)$, but the majority $(n=10)$ showed reductions in its state of activation. In animal models, the patterns of c-Fos induction by systemic morphine have also been observed to be more interindividually variable in the striatum of female rats than in their male comparison groups (D'Souza et al., 1999). The source of 
this variability is unknown at this time, and additional studies examining the effects of possible regulatory influences will be needed to clarify this issue.

An additional finding of this study is the involvement of the ventral pallidum/substantia innominata $\mu$-opioid system in responses to sustained pain in humans. In a previous study, using similar techniques and using a mostly male sample, this brain region was part of a larger area of $\mu$-opioid system activation that included the adjacent nucleus accumbens (Zubieta et al., 2001). Different $\mu$-opioid system responses in the ventral pallidum/ substantia innominata and the nucleus accumbens of women allowed for a clearer delineation of their boundaries. $\mu$-Opioid system activation in the ventral pallidum/substantia innominata was also associated with the suppression of the negative affective state induced by the experience of pain, but not with the characteristics of the pain itself as rated by the MPQ scale. This finding appears consistent with some of the known functions of this brain region. The ventral pallidum and substantia innominata form part of the "extended amygdala" and have extensive reciprocal connections with the nucleus accumbens, prefrontal cortex, amygdala, and ventral tegmental area, which are modulated by $\mu$-opioid receptors (Russchen et al., 1985; Spooren et al., 1991; Chrobak and Napier, 1993; Johnson and Napier, 1997; Bourgeais et al., 2001). The ventral pallidum and substantia innominata have been implicated in the assessment of "stimulus salience" (i.e., the regulation of motivated behavior and stimulus-conditioned responses, whether in response to rewarding or aversive stimuli, by the integration of sensory, emotional, and cognitive information with motor responses) (Austin and Kalivas, 1991; Hernandez et al., 1991; Morris et al., 1998; Napier and Mitrovic, 1999; Taylor et al., 2000).

The present report demonstrates sex differences in the magnitude and direction of response of the $\mu$-opioid system to an intensity-matched, sustained deep somatic pain challenge involving antinociceptive and motivational-integrative neuronal networks. Age and reproductive status (Gabilondo et al., 1995; Zubieta et al., 1999), the presence of certain genetic polymorphisms (Mogil et al., 2000), and sex differences in the function of antinociceptive circuitry, as shown here, may contribute to individual response variations to clinical and experimental deeptissue pain.

\section{REFERENCES}

Akil H, Watson S, Young E, Lewis M, Khachaturian H, Walker J (1984). Endogenous opioids: biology and function. Annu Rev Neurosci 7:223-255.

Aloisi AM, Albonetti ME, Carli G (1994a) Sex differences in the behavioural response to persistent pain in rats. Neurosci Lett 179:79-82.

Aloisi AM, Steenbergen HL, van de Poll NE, Farabollini F (1994b) Sex-dependent effects of restraint on nociception and pituitary-adrenal hormones in the rat. Physiol Behav 55:789-793.

Austin M, Kalivas P (1991) Dopaminergic involvement in locomotion elicited from the ventral pallidum/substantia innominata. Brain Res 542:123-131.

Baamonde A, Hidalgo A, Andres-Trelles F (1989) Sex-related differences in the effects of morphine and stress on visceral pain. Neuropharmacology 28:967-970.

Basbaum A, Fields H (1984) Endogenous pain control system: brain spinal pathways and endorphin circuitry. Annu Rev Neurosci 7:309-338

Bourgeais L, Gauriau C, Bernard J (2001) Projections from the nociceptive area of the central nucleus of the amygdala to the forebrain: a PHA-L study in the rat. Eur J Neurosci 14:229-255.

Bushnell MC, Duncan GH (1989) Sensory and affective aspects of pain perception: is medial thalamus restricted to emotional issues? Exp Brain Res 78:415-418.

Carr K, Bak T (1988) Medial thalamic injection of opioid agonists: $\mu$-agonist increases while $\kappa$-agonist decreases stimulus thresholds for pain and reward. Brain Res 441:173-184.
Casey K (1999) Forebrain mechanisms of nociception and pain: analysis through imaging. Proc Natl Acad Sci USA 96:7668-7674.

Caterina M, Leffler A, Malmberg A, Martin W, Trafton J, Petersen-Zeitz K, Koltzenburg M, Basbaum A, Julius D (2000) Impaired nociception and pain sensation in mice lacking the capsaicin receptor. Science 288:306-313

Chrobak J, Napier T (1993) Opioid and GABA modulation of accumbens-evoked ventral pallidal activity. J Neural Transm Gen Sect 93:123-143.

Cicero TJ, Nock B, Meyer ER (1996) Gender-related differences in the antinociceptive properties of morphine. J Pharmacol Exp Ther 279:767-773

Cicero TJ, Ennis T, Ogden J, Meyer ER (1999) Gender differences in the reinforcing properties of morphine. Pharmacol Biochem Behav 65:91-96.

Coghill R, Sang C, Maisog J, Iadarola M (1999) Pain intensity processing within the human brain: a bilateral, distributed mechanism. J Neurophysiol 82:1934-1943.

Dannals R, Ravert H, Frost J, Wilson A, Burns H, Wagner HJ (1985) Radiosynthesis of an opiate receptor binding radiotracer: $\left[{ }^{11} \mathrm{C}\right]$ carfentanil. Int J Appl Radiat Isot 36:303-306.

Dawson-Basoa M, Gintzler A (1993) 17- $\beta$-estradiol and progesterone modulate an intrinsic opioid analgesic system. Brain Res 601:241-245.

D'Souza DN, Harlan RE, Garcia MM (1999) Sexual dimorphism in the response to $N$-methyl-D-aspartate receptor antagonists and morphine on behavior and c-Fos induction in the rat brain. Neuroscience 93:1539-1547.

Eckersell C, Popper P, Micevych P (1998) Estrogen-induced alteration of $\mu$-opioid receptor immunoreactivity in the medial preoptic nucleus and medial amygdala. J Neurosci 18:3967-3976.

Fillingim R, Maixner W (1995) Gender differences in the responses to noxious stimuli. Pain Forum 4:209-221.

Fillingim R, Ness J (2000) Sex-related hormonal influences on pain and analgesic responses. Neurosci Biobehav Rev 24:485-501.

Friston KJ, Frith CD, Liddle PF, Frackowiak RSJ (1991) Comparing functional (PET) images: the assessment of significant change. J Cereb Blood Flow Metab 11:690-699.

Friston KJ, Worsley KJ, Frackowiak RSJ, Mazziotta JC, Evans AC (1994) Assessing the significance of focal activations using their spatial extent. Hum Brain Mapp 1:210-220.

Friston KJ, Holmes AP, Worsley KJ, Poline J-P, Frith CD, Frackowiak RSJ (1995) Statistical parametric maps in functional imaging: a general linear approach. Hum Brain Mapp 2:189-210.

Gabilondo A, Meana J, Garcia-Sevilla J (1995) Increased density of $\mu$-opioid receptors in the postmortem brain of suicide victims. Brain Res 682:245-250.

Gear R, Levine J (1995) Antinociception produced by an ascending spino-supraspinal pathway. J Neurosci 15:3154-3161.

Gear R, Miaskowski C, Gordon N, Paul S, Heller P, Levine J (1996) $\kappa$-opioids produce significantly greater analgesia in women than in men. Nat Med 2:1248-1250.

Gear R, Aley K, Levine J (1999) Pain-induced analgesia mediated by mesolimbic reward circuits. J Neurosci 19:7175-7181.

Gross-Isseroff R, Dillon K, Israeli M, Biegon A (1990) Regionally selective increases in $\mu$ opioid receptor density in the brains of suicide victims. Brain Res 530:312-316.

Hammer RP (1990) $\mu$-opiate receptor binding in the medial preoptic area is cyclical and sexually dimorphic. Brain Res 515:187-192.

Harte S, Lagman A, Borszcz G (2000) Antinociceptive effects of morphine injected into the nucleus parafascicularis thalami of the rat. Brain Res 874:78-86.

Hernandez L, Valentine J, Powell D (1991) Opioid modulation of pavlovian learning in rabbits: involvement of sublenticular pathways. Behav Neurosci 105:431-442.

Jewett D (2001) A simple synthesis of $\left[{ }^{11} \mathrm{C}\right]$ carfentanil. Nucl Med Biol 28:733-734.

Johnson P, Napier T (1997) Morphine modulation of GABA- and glutamate-induced changes of ventral pallidal neuronal activity. Neuroscience 77:187-197.

Jones A, Kitchen N, Watabe H, Cunningham V, Jones T, Luthra S, Thomas D (1999) Measurement of changes in opioid receptor binding in vivo during trigeminal neuralgic pain using $\left[{ }^{11} \mathrm{C}\right]$ diprenorphine and positron emission tomography. J Cereb Blood Flow Metab 19:803-808.

Kavaliers M, Colwell D (1991) Sex differences in opioid and non-opioid mediated predator-induced analgesia in mice. Brain Res 568:173-177.

Kest B, Sarton E, Dahan A (2000) Gender differences in opioidmediated analgesia: animal and human studies. Anesthesiology 93:539-547.

Laruelle M (2000) Imaging synaptic neurotransmission with in vivo binding competition techniques: a critical review. J Cereb Blood Flow Metab 20:423-451.

Logan J, Fowler JS, Volkow ND, Wang GJ, Ding YS, Alexoff DL (1996) Distribution volume ratios without blood sampling from graphical analysis of PET data. J Cereb Blood Flow Metab 16:834-840.

Malmberg A, Chen C, Tonegawa S, Basbaum A (1997) Preserved acute 
pain and reduced neuropathic pain in mice lacking PKC $\gamma$. Science 278:279-283.

Manning B (1998) A lateralized deficit in morphine antinociception after unilateral inactivation of the central amygdala. J Neurosci 18:9453-9470.

Matthes HWD, Maldonado R, Simonin F, Valverde O, Slowe S, Kitchen I, Befort K, Dierich A, LeMeur M, Dolle P, Tzavara E, Hannoune J, Roques BP, Kieffer BL (1996) Loss of morphine-induced analgesia, reward effect, and withdrawal symptoms in mice lacking the $\mu$-opioidreceptor gene. Nature 383:819-823.

Melzack R, Katz J (2000) The McGill pain questionnaire: appraisal and current status. In: Handbook of pain assessment (Turk D, Melzack R, eds), pp 152-168. New York: Guilford.

Meyer CR, Boes JL, Kim B, Bland PH, Zasadny KR, Kison PV, Koral K, Frey KA, Wahl RL (1997) Demonstration of accuracy and clinical versatility of mutual information for automatic multimodality image fusion using affine and thin-plate spline warped geometric deformations. Med Image Anal 1:195-206.

Miaskowski C, Levine J (1999) Does opioid analgesia show a gender preference for females. Pain Forum 8:34-44.

Minoshima S, Koeppe RA, Mintun MA, Berger KL, Taylor SF, Frey KA, Kuhl DE (1993) Automated detection of the intercommissural line for stereotactic localization of functional brain images. J Nucl Med 34:322-329.

Mogenson G, Yang C (1991) The contribution of the basal forebrain to limbic-motor integration and the mediation of motivation to action. In: The basal forebrain: anatomy to function (Napier T, Kalivas P, Hanin I, eds), pp 267-290. New York: Plenum.

Mogil J, Belknap J (1997) Sex and genotype determine the selective activation of neurochemically-distinct mechanisms of swim stressinduced analgesia. Pharmacol Biochem Behav 56:61-66.

Mogil JS, Chesler EJ, Wilson SG, Juraska JM, Sternberg WF (2000) Sex differences in thermal nociception and morphine antinociception in rodents depend on genotype. Neurosci Biobehav Rev 24:375-389.

Morris J, Friston K, Büchel C, Frith C, Young A, Calder A, Dolan R (1998) A neuromodulatory role for the human amygdala in processing emotional facial expressions. Brain 121:47-57.

Napier T, Mitrovic I (1999) Opioid modulation of ventral pallidal inputs. Ânn NY Acad Sci 877:176-201.

Negus S, Mello N (1999) Opioid antinociception in ovariectomized monkeys: comparison with antinociception in males and effects of estradiol replacement. J Pharmacol Exp Ther 290:1132-1140.

Paulson P, Minoshima S, Morrow T, Casey K (1998) Gender differences in pain perception and patterns of cerebral activation during noxious heat stimulation in humans. Pain 76:223-229.

Price D (2000) Psychological and neural mechanisms of the affective dimension of pain. Science 288:1769-1772.

Romero M, Bodnar R (1986) Gender differences in two forms of coldwater swim analgesia. Physiol Behav 37:893-897.

Rubinstein M, Mogil JS, Japon M, Chan EC, Allen RG, Low MJ (1996) Absence of opioid stress-induced analgesia in mice lacking $\beta$-endorphin by site-directed mutagenesis. Proc Natl Acad Sci USA 93:3995-4000.

Russchen F, Amaral D, Price J (1985) The afferent connections of the substantia innominata in the monkey, Macaca fascicularis. J Comp Neurol 242:1-27.
Sinchak K, Micevych P (2001) Progesterone blockade of estrogen activation of $\mu$-opioid receptors regulates reproductive behavior. J Neurosci 21:5723-5729.

Smith Y, Zubieta J, Del Carmen M, Dannals R, Ravert H, Zacur H, Frost $\mathrm{J}$ (1998) Brain $\mu$ opioid receptor measurements by positron emission tomography in normal cycling women: relationship to $\mathrm{LH}$ pulsatility and gonadal steroid hormones. J Clin Endocrinol Metab 83:4498-4505.

Sora I, Takahashi N, Funada M, Ujike H, Revay RS, Donovan DM, Miner LL, Uhl GR (1997) Opiate receptor knockout mice define $\mu$ receptor roles in endogenous nociceptive responses and morphine-induced analgesia. Proc Natl Acad Sci USA 94:1544-1549.

Spooren W, Veening J, Groenewegen H, Cools A (1991) Efferent connections of the striatopallidal and amygdaloid components of the substantia innominata in the cat: projections to the nucleus accumbens and caudate nucleus. Neuroscience 44:431-447.

Stock H, Caldarone B, Abrahamsen G, Mongeluzi D, Wilson M, Rosellini $R$ (2001) Sex differences in relation to conditioned fear-induced enhancement of morphine analgesia. Physiol Behav 72:439-447.

Stohler C, Kowalski C (1999) Spatial and temporal summation of sensory and affective dimensions of deep somatic pain. Pain 79:165-173.

Taylor S, Liberzon I, Koeppe R (2000) The effect of graded aversive stimuli on limbic and visual activation. Neuropsychologia 38:1415-1425.

Terman G, Shavit Y, Lewis J, Cannon J, Liebeskind J (1984) Intrinsic mechanisms of pain inhibition: activation by stress. Science 226:1270-1277.

Tershner S, Mitchell J, Fields H (2000) Brainstem pain modulating circuitry is sexually dimorphic with respect to $\mu$ and $\kappa$ opioid receptor function. Pain 85:153-159.

Treede R-D, Kenshalo DR, Gracely RH, Jones AKP (1999) The cortical representation of pain. Pain 79:105-111.

Unruh A (1996) Gender variations in clinical pain experience. Pain 65:123-167

Watkins L, Mayer D (1982) Organization of endogenous opiate and nonopiate pain control systems. Science 216:1185-1192.

Watson D, Clark LA, Tellegen A (1988) Development and validation of brief measures of positive and negative affect: the PANAS scales. J Pers Soc Psychol 54:1063-1070.

Worsley K, Evans A, Marrett S, Neelin P (1992) A three-dimensional statistical analysis for CBF activation studies in human brain. J Cereb Blood Flow Metab 12:900-918.

Worsley KJ (1994) Local maxima and the expected euler characteristic of excursion sets of $x^{2}, \mathrm{~F}$, and t fields. Adv Appl Prob 26:13-42.

Zacny J (2001) Morphine responses in humans: a retrospective analysis of sex differences. Drug Alcohol Depend 63:23-28.

Zhang X, Ashton-Miller JA, Stohler CS (1993) A closed-loop system for maintaining constant experimental muscle pain in man. IEEE Trans Biomed Eng 40:344-352.

Zubieta J, Dannals R, Frost J (1999) Gender and age influences on human brain $\mu$ opioid receptor binding measured by PET. Am J Psychiatry 156:842-848.

Zubieta J, Smith Y, Bueller J, Xu Y, Kilbourn M, Meyer C, Koeppe R, Stohler C (2001) Regional $\mu$ opioid receptor regulation of sensory and affective dimensions of pain. Science 293:311-315. 